\title{
SORPTION OF LEAD ION FROM AQUEOUS SOLUTION BY CARBOXYLIC ACID GROUPS CONTAINING ADSORBENT POLYMER
}

\author{
MEHDI HOSSEINZADEH* \\ *Marand Faculty of Technical and Engineering, University of Tabriz, Tabriz, Iran \\ E-mail:mh_1268@yahoo.com \\ Telefax: +984142266741
}

\begin{abstract}
Novel method to synthesize of $p$-(2,2,3,3-tetracarboxylic acid cyclopropyl)phenyl acrylate( $P$-TCP) was disclosed. In this study,3-(4hydroxyphenyl)cyclopropane-1,1,2,2-tetracarboxylicacid was synthesized by the new method and reacted with acryloyl chloride to preparation of $P$-TCP monomer. Then the resulting monomer was polymerized by free-radical polymerization initiated with benzoyl peroxide in ethyl acetate a solvent to obtain a poly-(2,2,3,3- tetra carboxylic acid cyclopropyl)phenyl acrylate (PTCP)with multicarboxylic acid cyclopropane functionalities in the pendant group as a new polymer and applied to remove $\mathrm{Pb}(\mathrm{II})$ from aqueous solution. The sorption experiments under different experimental conditions such as, contact time, temperature and $\mathrm{pH}$ were investigated. The functionalized polymer showed strong adsorption ability to the $\mathrm{Pb}(\mathrm{II})$, with the maximum adsorption capacities of $553 \mathrm{mgg}^{-1}$ at $\mathrm{pH}$ of 5 . The high adsorption rate ( $<50 \mathrm{~min}$ ) was seen. The removal of $\mathrm{Pb}$ (II) by polymer followed the pseudo-second-order rate better than the pseudo-first-order. The removal mechanisms was described as a metal-binding organic ligand (-COOH) and the electrostatic attractions between Pb(II) and oxygenic functional groups. The synthesized monomer, polymer and its metal chelates were characterized by FT-IR, ${ }^{1} \mathrm{H}-\mathrm{NMR}$ spectroscopy, scanning electronic microscopy (SEM) and atomic absorption techniques (AAS).
\end{abstract}

Keywords: Adsorption, Free Radical Polymerization, Malononitrile, Metal ions, $p$-(tetracarboxylic acid cyclopropyl) phenyl acrylate.

\section{INTRODUCTION}

With the development of industry, heavy metal pollution has become a severe environmental issue. Unlike some organic pollutants, heavy metal ions cannot be decomposed and are not biodegradable ${ }^{1}$. They are causing damages to the environment and can also enter the food chain and adversely affecting the health of human life ${ }^{2-4}$. Hence, there are needed to remove heavy metals from the environmental and biological samples. The different method used for their removal from aqueous solution ${ }^{5-8}$. Among related techniques, adsorption is considered to be the most promising process due to its easy handling, high efficiency, selectivity and also the low cost possibilities ${ }^{9,10}$. Therefore, the effort has been made to design and prepare new sorbent functional polymers with excellent sorption performance. Functional groups on the adsorbent surface not only affect the adsorption selectivity but also dominate the adsorption mechanism. The functional groups on their surface polymer such as, carboxylic acid, amine, azide, tetrazole, sulfonic, phosphonic and hydroxyl are interest, mainly due to effective absorption of heavy metal ion ${ }^{11-14}$

The carboxylic acid-containing polymer is well-known for forming stable chelates with metal ions in aqueous solution. Immobilization of the carboxylic acid group on various supporting polymers is attracting widespread attention since chelating agents improve metal ion sorption ${ }^{15-19}$. Therefore, we attempted to prepare new chelating polymer materials containing carboxylic acid ligands, with high sorption capacity, high rate of sorption and low cost of sorbent with better analytical parameters in comparison with the similar samples ${ }^{20,21}$, which can be used in wastewater treatment. The aim of the present study is to evaluate sorption characteristics for $\mathrm{Pb}$ (II) metal ion from aqueous solutions by using a new synthesized polymer (PTCP) which contains carboxylic acid groups. The $P$ TCP monomer was synthesized by the reaction of 3-(4-hydroxy phenyl) cyclopropane-1,1,2,2-tetracarboxylic acid with acryloyl chloride and polymerized by free-radical polymerization method to obtain a polymer with multi carboxylic acid cyclopropane functionalities in the pendant group ${ }^{22}$. The resulting polymer was dispersed in aqueous solutions of $\mathrm{Pb}(\mathrm{II})$ and its metal sorption capacity was measured by atomic absorption techniques(AAS).

\section{EXPERIMENTAL}

\subsection{Chemicals and equipment}

$P$-Hydroxybenzaldehyde (Merck) was crystallized from water containing a small amount of sulfuric acid and dried under vaccume. Acrylonitrile (Merck, Germany) was distilled under normal pressure and stored in the refrigerator. Cyanogen bromide was synthesized based on reported reference ${ }^{23}$.Malononitrile, triethylamine,sodium hydroxide, Lead (II) Nitrate $\left.\mathrm{Pb}\left(\mathrm{NO}_{3}\right)_{2} \cdot 6 \mathrm{H}_{2} \mathrm{O}\right]$ and solvents were purchased from Merck or Aldrich and used without further purification.
Melting points were measured with a digital melting point apparatus (Electro thermal, UK). The ${ }^{1} \mathrm{HNMR}$ spectra were recorded on Bruker 300 FT-NMR at 300 $\mathrm{MHz}$ and obtained on the solution in acetone- $d_{6}$ and/or $\mathrm{CDCl}_{3}$ as solvent using TMS as the internal standard. The IR spectra were determined in the region 4000$400 \mathrm{~cm}^{-1}$ on a NEXUS 670 FT IR spectrometer (USA) by preparing KBr pellets. The metal adsorption capacities of polymers were measured by an AAS 670 Shimadzu atomic absorption spectrometer (Japan) in aqueous solution. Viscosity value was obtained by using a Cannon Fenske viscometer. Elemental analysis of the polymer was carried out using a EURO EA 3000 (Italy). The electron micrographs were obtained by using a scanning electron microscope (SEM) LEO 440i (UK).

\subsection{Preparation of 3-(4-hydroxy phenyl)-1,1,2,2-tetracyanocyclopropane}

A solution of $p$-Hydroxybenzaldehyde $(0.122 \mathrm{~g}, 1 \mathrm{mmol})$ in butanol $(10 \mathrm{~mL})$ was placed in Teflon-faced screw cap tube. The mixture was stirred on a magnetic stirrer, for minutes. Then malononitrile (132 mg, $2 \mathrm{mmol}$ ), triethylamine $(0.202 \mathrm{~g}, 2 \mathrm{mmol})$ was added too. The solution was cold down to $0-5^{\circ} \mathrm{C}$ and the cyanogen bromide $(0.106 \mathrm{~g}, 1 \mathrm{mmol})$ was added gently. Cream color solid precipitated during 15 minutes, After the completion of the reaction, the product was separated from the solution by filtration, washed with $15 \mathrm{ml}$ ether and dried to give $0.242 \mathrm{~g}$ of the product( yield: $100 \%$, mp $135-138^{\circ} \mathrm{C}$ ).

FT-IR (KBr): 3301(ar-OH), 3021(ar-C-H), 2273(CN nitrile), $\mathrm{cm}^{-1},{ }^{1} \mathrm{H}$ NMR (acetone- $\left.d_{6}\right) \delta 4.46(\mathrm{~s}, 1 \mathrm{H}$, cyclopropyl),5.08 $(\mathrm{s}, 1 \mathrm{H}$, Hydroxyl) $7.32(\mathrm{~d}, 2 \mathrm{H}, J=$ $8.7 \mathrm{~Hz}), 7.91(\mathrm{~d}, 2 \mathrm{H}, J=8.7 \mathrm{~Hz})$

\subsection{Preparation of 3-(4-hydroxy phenyl) cyclopropane-1,1, 2,2-} tetracarboxylicacid

A solution of $3.27 \mathrm{~g}$ (0.014 mol) 3-(4-hydroxy phenyl)-1,1,2,2tetracyanocyclopropane in $30 \mathrm{~mL}$ methanol and $20 \mathrm{~mL}$ of $25 \%$ aqueous sodium hydroxide was refluxed for $3 \mathrm{~h}$. The methanol was removed under vacuum and the residual liquid extracted with $10 \mathrm{~mL}$ ether to remove non-acidic products. The aqueous solution was acidified with dilute hydrochloric acid and once again extracted with $5 \mathrm{~mL}$ ether. The concentration of aqueous solution on reduced pressure solidified in water and dried to give $3.55 \mathrm{~g}$ of the product ( $81.7 \%$ yields).

FT-IR (KBr): 3493(-OH carboxyl), 1703(C=O carboxyl)

\subsection{Preparation of $\boldsymbol{P}$-TCP monomer}

Briefly, into a $100 \mathrm{~mL}$ round bottom flask equipped with a magnetic stirrer and dropping funnel, freshly distilled acryloyl chloride $(1.81 \mathrm{~g}, 0.02 \mathrm{~mol})$ in dry diethyl ether $(10 \mathrm{~mL})$ was added dropwise to a solution of 3-(4-hydroxy phenyl) cyclopropane-1,1,2,2-tetracarboxylic acid (5.6 g, $0.018 \mathrm{~mol})$,triethylamine $(2.02 \mathrm{~g}, 0.02 \mathrm{~mol})$, and diethyl ether $(30 \mathrm{ml})$ with stirring for $2 \mathrm{~h}$ at $0^{\circ} \mathrm{C}$. Then 
triethylamine hydrochloride was filtered off and rinsed with $30 \mathrm{~mL}$ ethyl acetate. Extractions were performed on the filtrate which was poured into a $200 \mathrm{~mL}$ beaker with $\mathrm{HCl}(100 \mathrm{~mL}, 1.0 \mathrm{~mol} / \mathrm{L})$ for a precipitate of the $p$-TCP monomer. Then, the product was collected and washed with dilute hydrochloric acid and dried to give $4.97 \mathrm{~g}$ of the monomer (yield: $76 \%, \operatorname{mp} 162-166^{\circ} \mathrm{C}$ ).

FT-IR (KBr): 3343(-OH carboxyl), 1723(C=O ester), 1694(C=O carboxyl), 1622 $(\mathrm{C}=\mathrm{C}$ alkene $), 1176-1223(\mathrm{C}-\mathrm{O}) \mathrm{cm}^{-1}$.

\subsection{Polymerization of $\boldsymbol{P}$-TCP}

A total of $(0.364 \mathrm{~g}, 1 \mathrm{mmol})$ of $P$-TCP solid was dissolved with about $6 \mathrm{~mL}$ of ethyl acetate in a polymerization tube. Then, benzoyl peroxide $(3.0 \mathrm{mg}, 0.018$ mmol) was added under nitrogen atmosphere. The polymerization tube was put into an oil bath with stirring when the oil bath was heated to $70^{\circ} \mathrm{Cand}$ it was shacked for $12 \mathrm{hr}$. The final obtained viscous product was poured into cyclohexane $(100 \mathrm{~mL})$ for the precipitate of the polymer. The obtained polymer was collected and washed with $30 \mathrm{ml}$ ethanol and dried under vacuum to give $0.287 \mathrm{~g}$ of PTCP(yield: $79 \%$ ).

$\eta_{\text {ninh }}=0.29 \mathrm{dL} / \mathrm{g}\left(\right.$ Concentration of $0.5 \mathrm{~g} / \mathrm{dL}$ in acetone at $\left.25^{\circ} \mathrm{C}\right)$.

FT-IR (KBr): 3352(-OH carboxyl), 2852, 2927 (aliph-C-H), 1728(C=O ester), $1692\left(\mathrm{C}=\mathrm{O}\right.$ carboxyl), $1166-1216(\mathrm{C}-\mathrm{O}$ ester $) \mathrm{cm}^{-1}$.

\subsection{Batch sorption experiment}

Batch sorption experiments were carried out to study the sorption performances of $\mathrm{Pb}$ (II) on PTCP. The PTCP $(100 \mathrm{mg})$ was stirred with excess metal salt $\left(500 \quad \mathrm{mgL}^{-1}\right)$ at a room temperature of $25^{\circ} \mathrm{C}$. In addition, the $\mathrm{pH}$ values of $\mathrm{Pb}$ (II) solution were adjusted to 1 to 7 by adding moderate $0.01 \mathrm{M} \mathrm{NaOH}$ or $\mathrm{HNO}$. The PTCP sorption kinetics for $\mathrm{Pb}$ (II) was carried out by shaking the mixture of adsorbent $(100 \mathrm{mg})$ and $\mathrm{Pb}$ (II) solution $\left(50 \mathrm{~mL}, 500 \mathrm{mgL}^{-1}, \mathrm{pH} 5.0\right)$ at different time intervals at $25^{\circ} \mathrm{C}$. The effect of temperature was explored by controlling the temperature at 25,40 and $55^{\circ} \mathrm{C}$ to study the sorption thermodynamics. The mixtures were vibrated for $6 \mathrm{~h}$ to ensure that the sorption process reached complete equilibrium and the filtrates were collected to measure the final ion concentration by atomic absorptions spectrophotometry (AAS). The adsorption capacities, $\left(\mathrm{mg} \mathrm{M}^{2+} / \mathrm{g}\right.$ resin) in various conditions were calculated as follows (Eq. 1):

$$
\mathrm{q}=\frac{\left(\mathrm{C}_{0}-\mathrm{C}_{\mathrm{f}}\right)}{\mathrm{w}} \times \mathrm{V}
$$

Where $\mathrm{C}_{0}$ and $\mathrm{C}_{\mathrm{f}}$ are the initial and final concentrations $\left(\mathrm{mgL}^{-1}\right)$ of metal ion in the aqueous solution, respectively, $\mathrm{V}$ is the volume of metal ion solution (50 $\mathrm{ml})$ and $\mathrm{W}$ is the weight of the new polymer $(100 \mathrm{mg})$.

\section{RESULTS AND DISCUSSION}

\subsection{Characteristics}

The 3-(4-hydroxy phenyl)-1,1,2,2-tetracyanocyclopropane (1)was prepared by the reactions of $p$-hydroxybenzaldehyde with malononitrile and cyanogen bromide (scheme 1).<smiles>CC(Br)(CC#N)c1cc(O)ccc1C=O</smiles><smiles>N#CC1(C#N)C(c2ccc(O)cc2)C1(C#N)C#N</smiles><smiles>CO[C@H](O)C(O)O</smiles><smiles>CC=CC(=O)Cl</smiles>

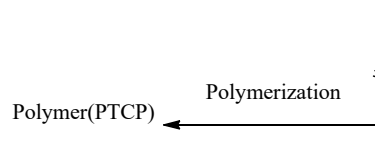<smiles>C=CC(=O)Oc1ccc(C2C(C(=O)O)(C(=O)O)C2(C(=O)O)C(=O)O)cc1</smiles>

Scheme 1. Synthetic route for the preparation of PTCP
The chemical structure of the resulting compound was confirmed by ${ }^{1} \mathrm{H}$ NMR, and IR spectroscopy techniques. Figure 1a displays the FT-IR spectrum of 1 .The spectrum showed that the formation of nitrile groups took place in about $2273 \mathrm{~cm}^{-1}$. The ${ }^{1} \mathrm{H}-\mathrm{NMR}$ spectrum of the 1 was shown in figure 2 . In this spectrum, a singlet at $\delta 4.46 \mathrm{ppm}$ corresponding to cyclopropyl C-H proton ${ }^{24}$, two doublets at $\delta 7.32$ and $7.91 \mathrm{ppm}(J=8.7 \mathrm{~Hz})$ for phenyl ring and a singlet at $\delta 5.08$ corresponds to hydroxyl proton.

The synthetic reaction for the formation of 2 is shown in Scheme 1 . We obtained the resulting material first, from basic hydrolyzing then acidic condition from material based on cyclopropane ring. The hydrothermal reaction of $\mathrm{NaOH}$ with 1 under reflux condition afforded the light cream color compound of 2 .

Figure $1 \mathrm{~b}$ displays the FT-IR spectrum of 2.The comparison of $1 \mathrm{a}$ and 1 bspectrum reveals that the nitrile peaks have disappeared completely and instead of the absorption peaks of $\mathrm{C}=\mathrm{O}$ carboxylate $1703 \mathrm{~cm}^{-1}$ and hydroxyl groups at a higher frequency at about $3493 \mathrm{~cm}^{-1}$ were appeared. The 3 monomer ( $p$-TCP) prepared by the well-known Schotten-Baumann method ${ }^{25}$ and FT-IR spectrum was shown in figure $1 \mathrm{c}$.In this spectrum, the adsorption peaks at $1723 \mathrm{~cm}^{-1}$ assigned to the $\mathrm{C}=\mathrm{O}$ indicates the formation of ester groups in the related monomer.

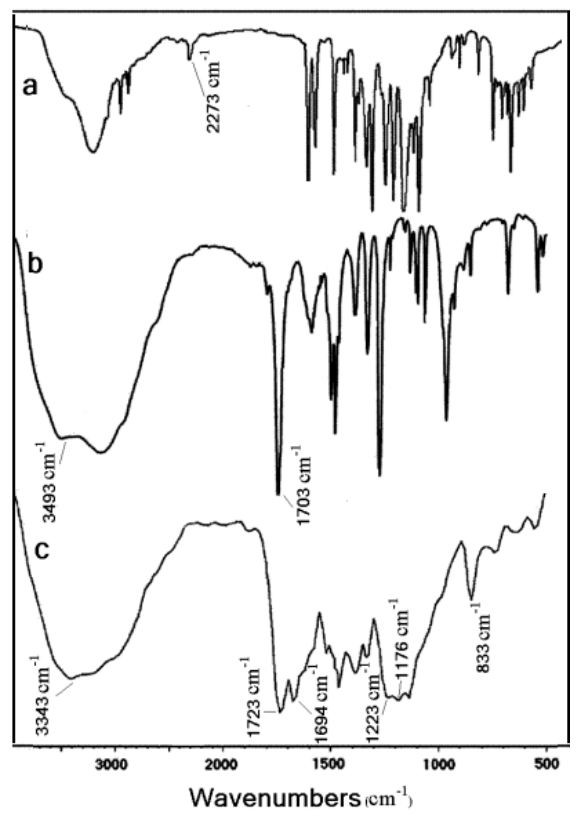

Figure 1. FT-IR spectrum:(a)3-(4-hydroxy phenyl)-1,1, 2,2tetracyanocyclopropane, (b) 3-(4-hydroxy phenyl) cyclopropane-1,1,2,2tetracarboxylic acid (c) $p$-TCP.

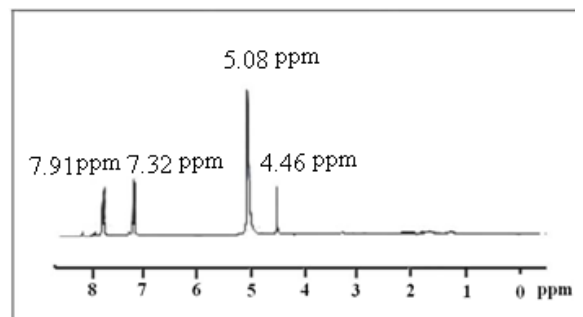

Figure 2. Characterized ${ }^{1} \mathrm{HNMR}$ spectra of 3-(4-hydroxy phenyl)-1,1, 2,2tetracyanocyclopropane.

The $p$-TCP monomer was polymerized by free radical polymerization with benzoyl peroxide as initiator to obtain the PTCP with multicarboxylic acid cyclopropane groups. The resulting monomer was quite reactive toward free radical polymerization and polymerized readily. The free radical initiator did not attack the cyclopropane ring containing carboxyl groups during polymerization. Considering the value of inherent viscosity $\left[\eta_{\text {ninh }}=0.29 \mathrm{dL} / \mathrm{g}\right]$, can be estimated that the molecular weight of PTCP is relatively low. The solubility of PTCP in various solvents is given in Table1. 
Table1. Solubility of PTCP in various organic solvents, Temp: $25^{\circ} \mathrm{C}, \mathrm{pH}: 6$.

\begin{tabular}{|c|c|c|c|c|c|c|c|c|}
\hline \multirow{2}{*}{ Polymer } & \multicolumn{8}{|c|}{ Solvent } \\
\hline & Distilled Water & Methanol & Diethyl ether & Ethyl acetate & Acetone & Dimethyl- formamide & Dimethyl- sulfoxide & n-Hexane \\
\hline РTCP & insoluble & insoluble & slightly soluble & soluble & soluble & soluble & soluble & insoluble \\
\hline
\end{tabular}

Insoluble $\left(<1 \mathrm{mg} \mathrm{mL}^{-1}\right)$, slightly soluble $\left(1-5 \mathrm{mg} \mathrm{mL}^{-1}\right)$, Soluble $\left(>5 \mathrm{mg} \mathrm{mL}^{-1}\right)$.

\subsection{Effect of pH and sorption mechanism}

Figure 3 presents the effect of $\mathrm{pH}$ values ranging from 2 to 7 on the removal of $\mathrm{Pb}(\mathrm{II})$ by the PTCP. The sorption of metal ions at $\mathrm{pH}$ values below 3 is low. This is probably due to the high concentration of $\mathrm{H}^{+}$, carboxylic groups are protonated preferably and metal uptake is decreased consequently. Carboxylic groups containing polymer are under carboxylate form which is favorable for $\mathrm{Pb}$ (II) complexation when $\mathrm{pH}$ is higher than 3 . The metal sorption capacity of the PTCP was measured with atomic absorption and UV-Vis spectroscopy methods. The sorption mechanisms mainly attributed to the metal-binding organic ligand $(-\mathrm{COOH})$ and the electrostatic attractions between $\mathrm{Pb}(\mathrm{II})$ and oxygenic functional groups.

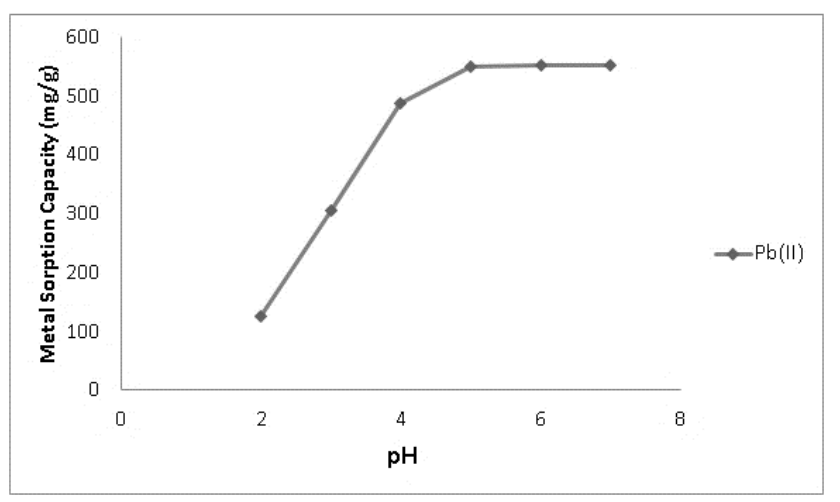

Figure 3. Effect of $\mathrm{pH}$ on the sorption of $\mathrm{Pb}(\mathrm{II})$ onto PTCP [initial metal concentration $500 \mathrm{mgL}^{-1}$, polymer $\left.(100 \mathrm{mg})\right]$

Above $\mathrm{pH}$ 2.6the carboxylic groups became a carboxylate form and thus the strong adsorption of PTCP to metal ions happened by electrostatic attractions mechanism (scheme2).
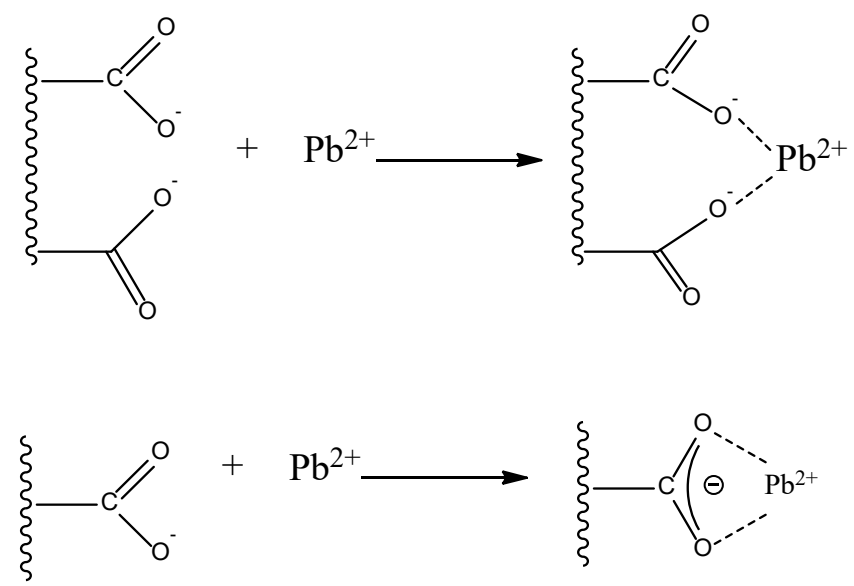

Scheme 2. Adsorption mechanism of PTCP for Lead ion.

The FT-IR spectra of PTCP before and after sorption Pb(II) are shown in Figure 4. This spectrum reveals that the characteristic peaks after sorption $\mathrm{Pb}$ (II) decrease, especially the peak of -OH groups abate obviously. It means plenty of carboxyl groups on the surface of polymer is consumed ${ }^{21}$. The carbonyl stretching of the carboxylate group is a small shift towards lower frequency, $1671 \mathrm{~cm}^{-1}$ related to the charge transfer from the carbonyl oxygen to the $\mathrm{Pb}(\mathrm{II})$ ion $^{26}$. This is indicative that $\mathrm{Pb}(\mathrm{II})$ formed complexes with the carboxyl groups.
Scanning electron micrographs (SEM) was utilized to study the morphology of the PTCP and its lead complex (prepared in $\mathrm{pH} 5$ ). Figure 5 shows that there is a strong change in morphology of polymer surface from PTCP beads in comparison with its metal complex. It can be concluded that the $\mathrm{Pb}$ (II) were bound with carboxyl groups in the polymer causes the surface smoother. The lead ions act as a bridge among the connected surface reactive sites, resulting in a smooth surface, which indicates the strong interactions of resin surface with $\mathrm{Pb}(\mathrm{II})$ ions in aqueous solution.

The comparative experiments between PTCP and other reported adsorbents containing carboxylate groups were investigated to illustrate the excellent adsorption performance of PTCP. The results indicate that the removal efficiencies of the prepared resin were higher or comparable, in some cases than that of other presented adsorbents. The results are shown in table 2 .

Table 2. Comparison of the maximum $\mathrm{Pb}$ (II) sorption capacity of on PTCP with other sorbents

\begin{tabular}{|l|c|c|}
\hline Adsorbents & $\begin{array}{c}\text { Sorption capacity (mg/g) } \\
\text { Pb(II) }\end{array}$ & Reference \\
\hline PTCP & 553 & This work \\
\hline EDTA-mGO & 508.4 & {$[21]$} \\
\hline $\mathrm{CSMA}_{-} \mathrm{AB}_{2}$ resin & 31 & {$[27]$} \\
\hline $\mathrm{Fe}_{3} \mathrm{O}_{4}-\mathrm{APTES}-\mathrm{EDTA}$ & 11.31 & {$[28]$} \\
\hline (CS/PEG/PAA) hydrogel & 431.7 & {$[29]$} \\
\hline (g-Gly/pAA) & 684.9 & {$[30]$} \\
\hline
\end{tabular}

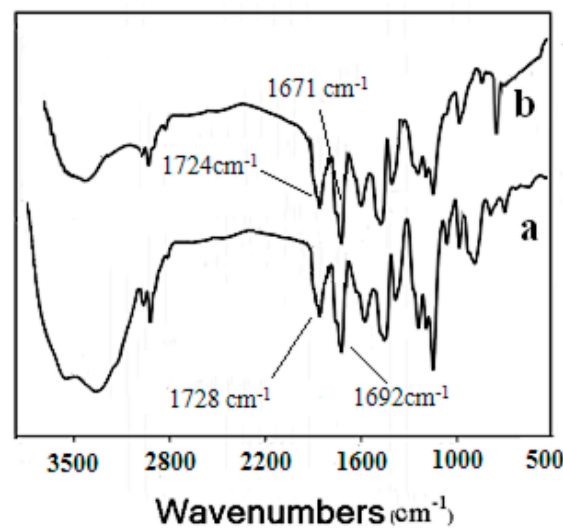

Figure 4. FT- IR spectra of (a) PTCP, (b) PTCP-Pb complex (numbers represent $\mathrm{pH}$ in which maximum metal sorption was obtained).

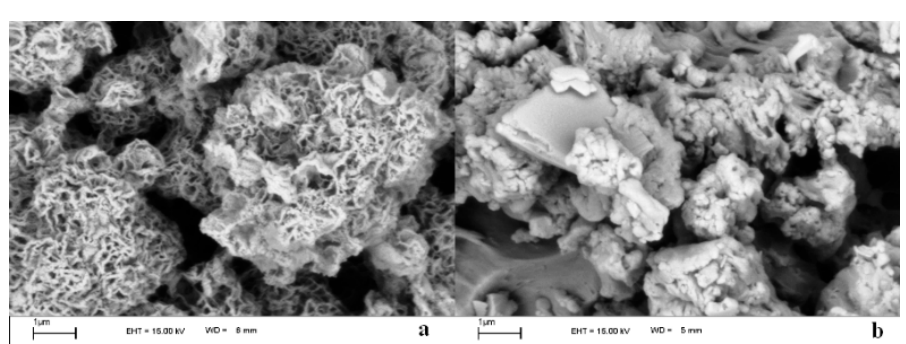

Figure 5. SEM images of: (a) PTCP, (b) PTCP-Pb complex (numbers represent $\mathrm{pH}$ in which maximum metal sorption was obtained). 


\subsection{Sorption kinetics}

The sorption of $\mathrm{Pb}(\mathrm{II})$ metal ions ( $\mathrm{mg} / \mathrm{g}$ ) on the new synthesized polymer is determined after different contact time intervals. Figure 6 shows the adsorption kinetic curve of the lead ion at $\mathrm{pH}$ 5. Maximum of the equilibrium sorption was seen within $50 \mathrm{~min}$ and then the rate of the sorption is increased slowly with the increasing of time and reached maximum equilibrium in $80 \mathrm{~min}$.

The pseudo-first-order and pseudo-second-order kinetic models have been showed the sorption mechanisms of PTCP and calculated as follows equations $\mathrm{s}^{31-}$ 32.

$$
\begin{aligned}
& \ln \left(\mathrm{q}_{\mathrm{e}}-\mathrm{q}_{\mathrm{t}}\right)=\ln \mathrm{q}_{\mathrm{e}}-\mathrm{k}_{1} \mathrm{t} \\
& \frac{\mathrm{t}}{\mathrm{q}_{\mathrm{t}}}=\frac{1}{\mathrm{k}_{2} \mathrm{q}_{\mathrm{e}}^{2}}+\frac{\mathrm{t}}{\mathrm{q}_{\mathrm{e}}}
\end{aligned}
$$

Where $\mathrm{q}_{\mathrm{t}}$ and $\mathrm{q}_{\mathrm{e}}$ are the adsorption amount at given time $\mathrm{t}$ and equilibrium time, respectively. $\mathrm{k}_{1}\left(\mathrm{mg} \mathrm{min}^{-1}\right)$ and $\mathrm{k}_{2}\left(\mathrm{mg} \mathrm{min}^{-1}\right)$ are the pseudo-first-order and the pseudo-second-order constant, respectively. The kinetics results obtained from the plots for sorption of $\mathrm{Pb}(\mathrm{II})$ onto PTCP are given in Table 3. The pseudosecond-order kinetic values agree perfectly well with experimental data of the removal of lead ion by the polymer according to the correlation coefficients $\left(\mathrm{R}^{2}\right)$ of the linear plots.

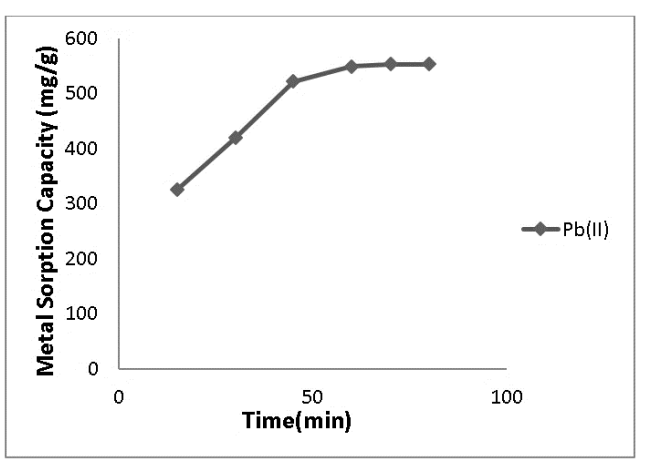

Figure 6. Effect of contact time on the sorption of $\mathrm{Pb}(\mathrm{II})$ by the PTCP (metal ion initial concentration $\left.500 \mathrm{mgL}^{-1}, \mathrm{pH}=5\right)$.

Table3. Kinetic parameters of $\mathrm{Pb}(\mathrm{II})$ sorption on the PTCP.

\begin{tabular}{|c|c|c|c|c|c|c|}
\hline $\begin{array}{c}\text { Metal } \\
\text { ion }\end{array}$ & \multicolumn{3}{|c|}{ Pseudo-first order model } & \multicolumn{3}{c|}{ Pseudo-second order model } \\
\hline \multirow{2}{*}{$\mathrm{Pb}(\mathrm{II})$} & $\mathrm{q}_{\mathrm{e}}(\mathrm{mg} / \mathrm{g})$ & $\mathrm{k}_{1}\left(\mathrm{mg} \mathrm{min}^{-1}\right)$ & $\mathrm{R}^{2}$ & $\mathrm{q}_{\mathrm{e}}(\mathrm{mg} / \mathrm{g})$ & $\mathrm{k}_{2}\left(\mathrm{mg} \mathrm{min}^{-1}\right)$ & $\mathrm{R}^{2}$ \\
\cline { 2 - 7 } & 46.69 & 0.0268 & 0.741 & 479.1 & 0.0015 & 0.989 \\
\hline
\end{tabular}

\subsection{Effect of temperature}

The effect of temperature on the adsorption reaction for metal ions is regarded as one of the important characteristics that can decide the efficiency of adsorption. Figure 7 shows that the adsorption capacities of $\mathrm{Pb}$ (II) increased with increasing temperature from $25^{\circ} \mathrm{C}$ to $55^{\circ} \mathrm{C}$, confirming that the adsorption process was endothermic.

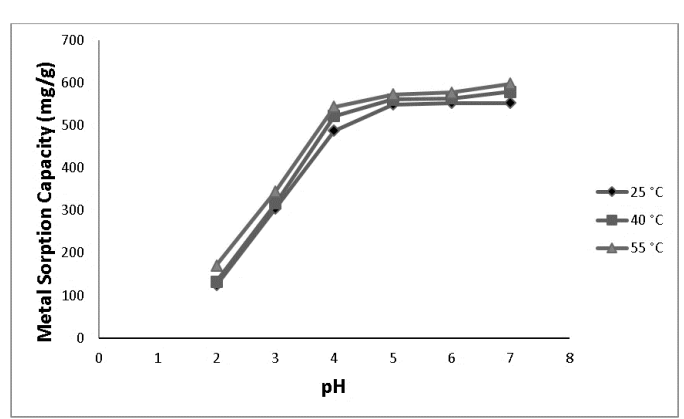

Figure 7. Adsorption isotherms of $\mathrm{Pb}$ (II) on PTCP at different temperatures $(\mathrm{pH}=5.0,70 \mathrm{~min})$.

\subsection{Desorption study}

Desorption of $\mathrm{Pb}$ (II) from the chelating PTCP was also studied in a batch experimental setup. The chelating polymer beads which were loaded by the maximum amounts of the respective metal ions at $\mathrm{pH} 5$ were placed in the medium containing $1 \mathrm{M} \mathrm{HCl}$ for $2 \mathrm{~h}$. The amount of desorbed metal ion was measured in solution. The result indicates that $\mathrm{Pb}(\mathrm{II})$ has a desorption ratio up to $89 \%$.

\section{CONCLUSIONS}

We synthesized a new polymer containing four carboxylic groups in each repeating cyclopropane ring. Spectral techniques such as FT-IR and ${ }^{1} H-N M R$ confirmed the structure of the resulting monomer and PTCP. The polymer was soluble in dimethyl formamide (DMF) and ethyl acetate, but was not soluble in water and tetra hydrofuran (THF) solvents. The carboxylic acid group containing PTCP could be used efficiently for removing $\mathrm{Pb}$ (II) from aqueous solutions by metal-binding organic ligand and electrostatic attractions mechanisms. FT-IR study on lead-polymer complex confirmed the presence of metal in polymer and the SEM micrographs possessed a smooth surface for PTCP-Pb complex in comparison with the non-complexed polymer. The adsorption of lead ion in high acidic medium was moderate, and it was favored at the $\mathrm{pH}$ value above 3 . The adsorption rate of polymer was fast and the largest fraction of the adsorbed metal ion by the polymer was obtained within $50 \mathrm{~min}$. The adsorption kinetics followed the pseudo-second-order kinetic equation. The PTCP is reusable adsorbent for the fast and highly efficient sorption of lead ion which demonstrated that, it was suitable for reuse in the removal of metal ions from contaminated aquatic systems.

\section{ACKNOWLEDGEMENTS}

The author wish to acknowledge financial supports from the University of Tabriz.

\section{REFERENCES}

1. A. Petrovic, M. Simonic, Int. J. Environm. Sci. Technol. 13, 1761 (2016).

2. N.Isobe, X.Chen, U.Kim,S. Kimura,M. Wada,T. Saito, J. Hazard. Mater. 260,195, (2013).

3. N.Lajçi, M. Sadiku, X. Lajçi, B. Baruti, S.Nikshiq, J. Int. Environ.Appl.Sci.12, 112 (2017).

4. N.K.Srivastava, C.B.Majumder,J. Hazard. Mater.151,1, (2008).

5. Y.Huang, X.Zeng, L.Guo, J.Lan, L.Zhang, D.Cao, Sep. Purif. Technol. 194,462, (2018).

6. A. S. Raeissi, M. Shahadat, R. Bushra, S. A. Nabi, Arab. J. Sci. Eng.43, 3601, (2018).

7. M. Naushad and Z.A.Alotman, Desaline.Water.Treat.J. 53,2158 , (2015)

8. G.Ozkula, B.Furbano, B.Rivas, N.Kabay, M.Bryjak, J. Chil. Chem. Soc. $61,2752,(2016)$.

9. R. Zhang,C.L.Chen,J.Li,X.K. Wang, J.Colloid Interface. Sci. 460,237, (2015)

10.S. L. Luo, X.J.Li, L.Chen, J.L.Chen, Y.Wan and C.B.Liu, Chem. Eng. J. 239, $312,(2014)$.

11.D.Zhao, Z.Zhang, H.Xuan, Y.Chen, K.Zhang,A.Alsaedi, J. Colloid Interface Sci. 506,300, (2017).

12.M.Hosseinzadeh, P.Najafi Moghadam and N.NorooziPesyan, J. Polym.Mater.34,363 (2017).

13.B.Sherino, S. Mohamad, N. S. Abdul Manan, H. Tareen, B. M. Yamin, S. N. Abdul Halim, Transit. Metal.Chem, 43, 53, (2018).

14.B.M.Cordova, C.R.Jacinto, H. Alarcon,L.M. Mejia,R.C. Lopez, D.O. Silva, E.T.G. Caval -heiro, T. Venancio, J.Z. Davalos, A.C. Valderrama, Int. J. Biol. Macromol ,120,2259, (2018).

15. Y.Huang, C.R. Li,L. Zhang, Appl. Mater.Interfaces. 6,19766, (2014)

16. E.Repo, L.Malinen, R.Koivula, R.Harjula, M.Sillanpää, J. Hazard.Mater. 187,122, (2011)

17. R.G.Huamani-Palomino, C. R.Jacinto, H.Alarcón, I.M.Mejía, R.C.López, D. O.Silva, E. T.G. Cavalheiro, T.Venâncio, J. Z.Dávalos, AC.Valderrama, Int. J. Biol. Macromol, In Press, https:// doi.org/10.1016/j.ijbiomac.2018.09.096.

18. Z.S.Liu1, G.L.Rempel,Hydrol Current Res. 2,1, (2011).

19. J.Faryza,K.Muhanna,D.Dari,J. Macromol. Sci., Pure Appl. Chem. 49,15,(2012).

20. N.K.M.Kame, E.M.Sayyah,A.A. Abdel-aal1, Appl. Sci. Res.3,448,(2013).

21. L.Cui,Y. Wang, L.Gao, L.Hu,L.Yan, Chem. Eng. J.281,1, (2015).

22. J.Lee, K.Kim, A.B.Padias,Polym. Bull.31,517, (1993). 
23. W.W.Hartman, E.E.Dreger,Org. Synth. Coll.2,150, (1943).

24. N.NorooziPesyan, M.Kimia, M.Jalilzadeh, E.J.Şahin, Chin.Chem.Soc.60, 35, (2013).

25. M.Tsuda,Schotten-Baumann Esterification of Poly(viny1 alcohol). Government Chemical Industrial Research Institute, Tokyo, 1963.

26. C-C.Wang,C-Y Chang,C-Y. Chen,Macromol. Chem. Phys.202,882, (2001)

27. R.Hasanzadeh, P.NajafiMoghadam, N.Samadi, Polym.Adv.Technol. 24,34,(2013).

28. J.K.Sahoo, A.Kumar, L.Rout, J.Rath, P.Dash, H.Sahoo, Sep. Sci. Technol.53,863, (2018).
29. J.Yu, J.Zheng, Q.Lu, S.Yang, X.Zhang, X. Wang, W.Yang, Colloid. Polym. Sci.294,1585, (2016).

30. A. Pal, D. Das, A. K. Sarkar, S. Ghorai, R. Das, S. Pal, Eur. Polym. J.66,33, (2015).

31. C.L.Chen, X.K.Wang, M.Nagatsu, Environ. Sci. Technol. 43,2362, (2009).

32. C.L.Chen, J.Hu, D.D. Shao,J.X. Li, X.K. Wang, J. Hazard. Mater.164,923, (2008). 